\title{
Endocrine correlates of intra-specific variation in the mating system of the St. Peter's fish (Sarotherodon galilaeus)
}

\author{
Albert F.H. Ros, ${ }^{\mathrm{a}, *}$ Adelino V.M. Canario, ${ }^{\mathrm{b}}$ Elsa Couto, ${ }^{\mathrm{b}}$ IIja Zeilstra, ${ }^{\mathrm{a}}$ and Rui F. Oliveira ${ }^{\mathrm{a}}$ \\ ${ }^{a}$ Unidade de Investigação em Eco-Etologia, Instituto Superior de Psicologia Aplicada, Rua Jardim do Tabaco 34, 1149-041, Lisboa, Portugal \\ ${ }^{\mathrm{b}}$ Centro de Ciências do Mar, Universidade de Algarve, Campus de Gambelas, 8005-139 Faro, Portugal
}

Received 10 February 2003; revised 7 June 2003; accepted 23 June 2003

\begin{abstract}
The Challenge Hypothesis postulates that androgen levels are a function of the social environment in which the individual is living. Thus, it is predicted that in polygynous males that engage in social interactions, androgen levels should be higher than in monogamous animals that engage in parental care. In this study, we tested this hypothesis at the intra-specific level using a teleost species, Sarotherodon galilaeus, which exhibits a wide variation in its mating system. Experimental groups of individually marked fish were formed in large ponds with different operational sex-ratios (OSR) to study the effects of partner availability on blood plasma levels of sex steroids [11-ketotestosterone (11-KT), testosterone (T), and 17,20 $\beta$-dihydroxy-4-pregnen-3-one (17,20 $\beta$-P)] and gonadosomatic index (GSI). Polygyny mostly occurred in the female biased OSR groups. 17,20 $\beta$-P and gonadosomatic index did not differ among OSR groups. However, 11-KT was high in male biased OSR and positively correlated with aggressive challenges, thereby supporting the central postulate of the Challenge Hypothesis. The results of $\mathrm{T}$ were the inverse of those of 11-KT, probably because 11-KT is metabolized from T. 11-KT levels of polygynous males did not differ neither from those of monogamous males, nor from those of males that participated in parental care. These results do not support the expected relationships between polygyny, parental care, and androgen levels. The differences from expectations for 11-KT may be related to the fact that in S. galilaeus, the mating and the parenting phase are not clearly separated and thus, males may still fight and court while they are brooding.
\end{abstract}

(C) 2003 Elsevier Inc. All rights reserved.

Keywords: 11-ketotestosterone; Testosterone; 17,20 $\beta$-dihydroxy-4-pregnen-3-one; Gonadosomatic index; Sarotherodon galilaeus; Aggression; Mating system; Parental care; Operational sex-ratio; St. Peter's fish

\section{Introduction}

Androgens play an important role in the organization and activation of agonistic behavior via age- and seasonallydependent mechanisms (Nelson, 1999). However, the expected positive relationship between androgens and aggression has not always been apparent even after the development of sensitive radioimmunoassays made it possible to measure hormones from small blood samples taken from free-living animals. Evidence has accumulated that shows that androgens are not only a causal factor of reproductive behaviors, but that they are also modulated by the

* Corresponding author. Fax: +351-218860954.

E-mail address: aros@ispa.pt (A.F.H. Ros). social environment in which the animal is inserted, as proposed in the "Challenge Hypothesis" (Wingfield, 1984b; Wingfield and Moore, 1987; Wingfield et al., 1990). Because high levels of testosterone have been found to be costly to maintain (e.g., Ketterson and Nolan, 1992; Wingfield et al., 1990), social modulation of testosterone levels has been interpreted as an adaptation for the individual to fine-tune its motivation to express agonistic behavior to the social challenges it receives (Oliveira et al., 2001b; Oliveira et al., 2002).

Monogamous and polygynous males typically differ in the expression of parental care, being higher in monogamous males, and in male-male competition, generally higher in polygynous males. A trade-off between androgens and parental care has been described for a number of bird species (e.g., Hegner and Wingfield, 1986; Oring et al., 
1988; Wingfield et al., 1990; Ketterson and Nolan, 1992; Silverin, 1993). Therefore, in monogamous males androgen levels should increase above reproductive baseline levels only when challenged by other males or by mating. In contrast, in polygynous males androgen levels are expected to be high throughout the breeding season due to the high levels of social interactions to which these males are exposed (Wingfield et al., 1990).

In turn, androgens may play a role in regulating motivational systems to the extent that polygyny is more likely to occur (Beletsky et al., 1995; De Ridder et al., 2000; Oliveira et al., 2001c). Steroid hormones, among them testosterone, increase the expression of secondary sexual characters that are used in male-male competition and mate choice (Owens and Short, 1995; Kimbal and Ligon, 1999). Testosterone also facilitates social behavior leading to an increase in encounters with potential mates, and/or an increase in territory size that might include several females (Wingfield et al., 1990; Ketterson and Nolan, 1992).

The St. Peter's fish, Sarotherodon galilaeus, has a wide variation in male mating strategies, which are expressed according to female availability (Balshine-Earn, 1996; Balshine-Earn and Earn, 1998; Fishelson and Hilzerman, 2002). This makes it an excellent model species to study the relationships between androgen levels and variation in the mating system. Males may defend territories or not, may participate in parental care by mouth-brooding part of the clutch or may refuse to incubate the eggs, and may pair consecutively with the same female (monogamy) or may expel the female from their territory and search for another mate (polygyny) (Schwanck and Rana, 1991; Balshine Earn, 1997; Fishelson and Hilzerman, 2002). The main aim of this study was to test in St. Peter's fish the following predictions derived from the challenge hypothesis: (1) Higher levels of agonistic challenges are correlated with higher levels of androgens; (2) Higher levels of androgens are correlated with polygynous behavior; (3) A trade-off exists between higher levels of androgens and male parental care. For this purpose, the operational sex-ratio (OSR) of large groups of reproductively active males and females in large ponds was manipulated and behavioral, morphological, and endocrine data were collected.

\section{Material and methods}

\section{Animals and housing conditions}

One-year-old Sarotherodon galilaeus, 127 males and 125 females with common life histories, were obtained from a stock of commercially bred fish, originating from the original local fish population (Ben-Tuvia et al., 1992), at the Experimental Station for Aquaculture (Min. of Agriculture, Dept. of Fisheries) at Lake Kinneret, Israel. The experiment was conducted from May to July 1999. Indoor-concrete ponds of $6 \times 2 \mathrm{~m}$ were filled with water up to a height of
$30 \mathrm{~cm}$ and received natural light (sunrise at 5:30h and sunset at 19:45h). Some structures were provided on the bottom of the ponds that could be used by the fish both as shelters and as landmarks for territories. The water in the ponds was flow-through taken from Lake Kinneret and continuously aerated. The water temperature fluctuated between 24 and $29^{\circ} \mathrm{C}$, which reflected the natural variation of water temperature in Lake Kinneret. Fish were fed every two days with floating pellets (Zemach, Israel). Additionally the fish were feeding on algae growing in the ponds.

\section{Experimental design}

Three concrete ponds were randomly assigned to different experimental treatments:(1) a male biased OSR group, which had twice as many males as females;(2) a control group, which had a balanced OSR; (3) a female biased OSR group, which had twice as many females as males. Every pond had 21 individuals and four replicates were obtained for every experimental treatment comprising 12 experimental trials. Fish were acclimated to the indoor ponds for one week before the start of the experiment. At the start of each experimental trial the sex of the fish was determined by inspection of the shape of the genital papillae (females have a wide T-shaped slit and males have a single circular orifice, Balshine-Earn, 1996), and by applying a light pressure to the abdomen, which in males generally causes the release of urine whereas females almost never released urine (Ros, personal observations). Examination of the gonads (see next section) showed that eight out of 252 fish were wrongly sexed. The resulting OSR $[0: 9]$ in the ponds was on average 2.23:1, 1.15:1, and 1:2.5. Each fish was marked with a unique combination of color beads (Rayher, indianerperlen, diameter $=4.5 \mathrm{~mm}$ ) on a fishing thread (Spécial Marine, super soft, diameter $=0.2 \mathrm{~mm}$ ) attached to the dorsal muscle.

\section{Blood sampling and analyses of gonads and steroids}

At the end of each experimental trial, the ponds were emptied and all fish were caught (duration 30 minutes, always between 10:00h and 12:00 h). Fish were anaesthetized in MS-222 (dilution 1:10000) and from every male a $0.3 \mathrm{ml}$ blood sample was drawn from the caudal vein with a $1 \mathrm{ml}$ syringe (taking about $1 \mathrm{~min}$ per male). Fish were then sacrificed by cutting the dorsal spine, weighed, and gonads were removed and weighed. Gonadosomatic index (GSI) was expressed as gonadal weight/body weight*100. Blood plasma was stored at $-20^{\circ} \mathrm{C}$ until steroid extraction. Free, sulphate, and glucuronide steroid fractions were extracted from $50 \mu \mathrm{l}$ plasma using the methodology described in Scott and Vermeirssen (1994). Steroid residues were resuspended in $1 \mathrm{ml}$ assay buffer and stored again at $-20^{\circ} \mathrm{C}$ until assayed for testosterone (T), 11-ketotestosterone (11KT) and 17,20 $\beta$-dihydroxy-4-pregnen-3-one (17,20 $\beta$-P). The radioimmunoassays and cross reactions for T, 11-KT, 
and for 17,20 $\beta$-P were described respectively in Scott et al. (1984), Kime and Manning (1982) and Canario et al., (1989). Intra-assay and inter-assay precision (coefficient of variation) were $4.6 \%$ and $15.5 \%$ for $17,20 \beta-\mathrm{P}, 7.5 \%$ and $12.4 \%$ for $\mathrm{T}$, and $8.2 \%$ and $11.6 \%$ for $11-\mathrm{KT}$.

\section{Classification of behavior}

Focal observations ( 20 min per male) were carried out once every 2 nd day for 14 days and the following data was collected: (1) Individuals that were paired. A pair was defined as two individuals that were consistently seen together courting and/or defending a territory during several observations; (2) Pairs that spawned; (3) Whether the male and/or the female of the pair that spawned picked up eggs for mouth brooding. In addition the following behaviors were recorded: (1) Aggressive behavior with two levels, Overt Aggression which included buts, bites and fast swimming towards the opponent, and Pendulum Threat in which the opponents approached each other with open mouth, but rarely grabbed and pulled the opponent's mouth; when behaviors were performed incomplete or at very low intensity, they were recorded as intent and weighed half in the analyses; (2) Tail-beating, a sudden slap of the tail directed toward the front or side of the opponent, was nearly exclusive between males and females; (3) Sexual behavior, the sum of all behaviors shown between partners before and during spawning which included: Quivering, a high frequency quiver over the horizontal axis of the body; Cleaning, Nibbling-off and transporting substrate away from the territory; and Skimming, male and female swimming in circles and frequently touching the substrate with their lower part of the body. The individual to whom behavior was directed or from which it was received was noted and this allowed the distinction of its own behavioral performance, i.e., behavior of the focal male towards other males or females; from behavioral challenges, i.e., behavior received by the focal male from other males or females.

\section{Data analyses and statistics}

The following questions have been asked to test the predictions derived from the challenge hypothesis (see introduction):

(1) What is the effect of manipulation of OSR on social behavior, sex-steroids and GSI? We expected male-male competition to be elevated in male-biased OSR and reduced in female-biased OSR, and consequently sex-steroids (in particular 11-KT) and GSI to vary with OSR.

(2) What is the relationship between mating stage and sex-steroids? We expected androgens to be high at the start of the mating cycle and to decrease after spawning. We expected 11-KT to be lowest in brooding males and $17,20 \beta$-P to be high in animals that spawned.

(3) What is the relationship between behavioral "strate- gies" after spawning and sex-steroids? We expected 11-KT to be high in males that adopted a polygynous strategy.

The following mating categories were defined: unpaired males, paired males that did not spawn (not considering male-male pairs), paired males that spawned but did not brood eggs and paired males that spawned and brooded eggs and fry. To study differences between behavioral "strategies", only males that spawned were considered. Three groups were defined: males that stayed with the partner after spawning (monogamous "decision"), males that deserted the partner (polygamous "decision"), and males that were deserted by the partner. Behavioral data were averaged over the whole observation period to study the effect of OSR and over the two last observation periods (i.e., the last four days of the experiment) to study the relationship with steroid hormones and mating strategies, so as to decrease variance in the generally low frequency behavioral events. Ten males had abnormal testes, i.e., had only one small rounded and clumped shape testis; in one case the testis appeared to be absent. Since our questions deal with male reproductive behavior these males were left out of all analyses.

To deal with behavioral data containing zero values and hormonal data containing outliers (see the large variation in some groups in Figs. 4 and 5) non-parametric stastics were used: Spearman rank correlation corrected for Bonferroni [Rs]. The Bonferroni rank and the total number of Spearman comparisons are indicated in parentheses after Rs; Friedman one-way ANOVA when comparing variables based on related samples [S(df)]; Kruskal-Wallis one-way ANOVA when comparing groups based on independent samples $[\mathrm{H}(\mathrm{df})]$. Anova's were followed by Dunn's post-hoc test (Zar, 1984).) Frequencies were analyzed by means of chisquare $\chi^{2}$. Analyses of behavioral data was based on 117 males and hormonal data on 109 males (it was not possible to take blood from 8 males), except when related to mating stage which were, respectively 109 and 101 (male-male pairs are not considered). The statistical package SPSS (release 11.0, SPSS Inc., www.spss.com) was used for statistical testing.

\section{Results}

Mating strategies, behavior, and the effect of OSR

\section{Frequencies of mating strategies}

Of ninety-five males that paired, $69 \%$ did it with one female partner, $22 \%$ paired with more than one female (average 2.3 females) and a few (8\%) paired with a male. Of the polygynous males only 5 males $(23 \%)$ had more than one female at the same time. Most heterosexual pairs (64\%) spawned and the female mouth brooded in all cases. In 50\% of the cases males also mouth brooded. Pair bond break-up (21 documented cases) initiated by desertion of the male $(57 \%)$ occurred mostly when OSR was female biased $\left(\chi_{2}^{2}=\right.$ $22, p<0.001)$ and the day after spawning took place $\left(\chi_{1}^{2}=\right.$ 

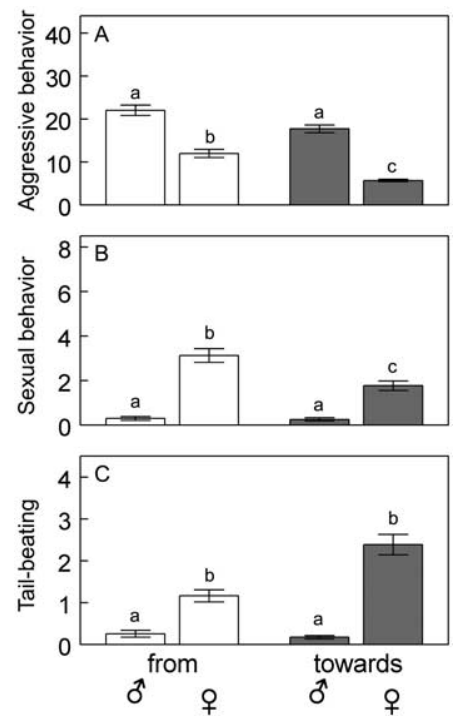

Fig. 1. Effect of social context on social behavior of males $(n=117)$. Data are expressed as mean \pm SEM, in frequency per 20 min focal observations. White bars: behavior received by the focal males from a male or female; Grey bars: behavior performed by the focal male towards a male or female. Different letters indicate statistically significant differences (Friedman oneway anova followed by Dunn's post-hoc test).

4.6, $p<0.05)$. Pair bond break-up initiated by desertion of the female $(43 \%)$ was independent of spawning and tended to be highest in male biased OSR $\left(\chi_{2}^{2}=5.5, p=0.06\right)$. All of the males found a new mate after deserting a female, whereas only one male found a new mate after being deserted by the female.

\section{Frequencies of behavior}

Aggressive behavior towards males was positively correlated with aggressive behavior received from males $[\operatorname{Rs}(4$, $66)=0.45, p<0.001]$. Aggressive behavior directed towards females did not significantly correlate with aggressive behavior received from females $[\operatorname{Rs}(25,66)=0.24$, NS].

Sexual behavior towards females was positively correlated with sexual behavior from females $[\operatorname{Rs}(3,66)=0.49$, $p<0.001]$, with tail-beating towards females $[\operatorname{Rs}(2,66)=$ $0.50, p<0.001]$ and with tail-beating received from females $[\operatorname{Rs}(6,66)=0.42, p<0.001]$. Also, sexual behavior received from females correlated positively with tail-beating received from females $[\operatorname{Rs}(1,66)=0.82, p<0.001]$. Aggressive behavior received from males was negatively correlated with sexual behavior $[\operatorname{Rs}(15,66)=0.34, p<$ $0.05]$ and tail-beating received from females $[\operatorname{Rs}(10,66)=$ $0.37, p<0.01]$.

\section{Operational sex-ratio}

Male-male aggression was more than twice as frequent as female-male aggression (Fig. 1A). Male-female aggression was mostly directed towards the female of a neighboring pair. Typically, males and females of both pairs were simultaneously performing threatening behavior by means of opening their mouth. In most of such ritualized fights between neighboring pairs, the females opposed each other and the males did the same. Males were significantly more aggressive towards other males when OSR was male biased (Figs. 2A-B).

Sexual behavior was almost exclusively received from females (Fig. 1B). Male-male sexual behavior occurred at low frequency in all different OSR groups (see above: 8 males had homosexual pair bonds). Sexual behavior received from females was higher in female biased groups (Fig. 2C), while there was no relationship between sexual behavior towards females and OSR (Fig. 2D).

Tail-beating occurred primarily in male-female interactions and rarely in male-male interactions (Fig. 1C). Tailbeating showed the same trend with regard to OSR as described above for sexual behavior (Fig. 2E-F).

\section{Mating stage}

Aggressive behavior was significantly different among mating stage (Figs. 3A-B). Post-hoc analyses showed that unpaired males were most aggressive and received most aggression, whereas males of the other mating categories did not differ amongst themselves in the frequency of aggressive behavior (Figs. 3A-B).

Sexual behavior was significantly different among mating stages with unpaired animals not receiving sexual behavior (Fig. 3C). Sexual behavior was increased in animals that deferred from brooding, and was strongly decreased in animals that engaged in mouth brooding (Fig. 3D). Tail-

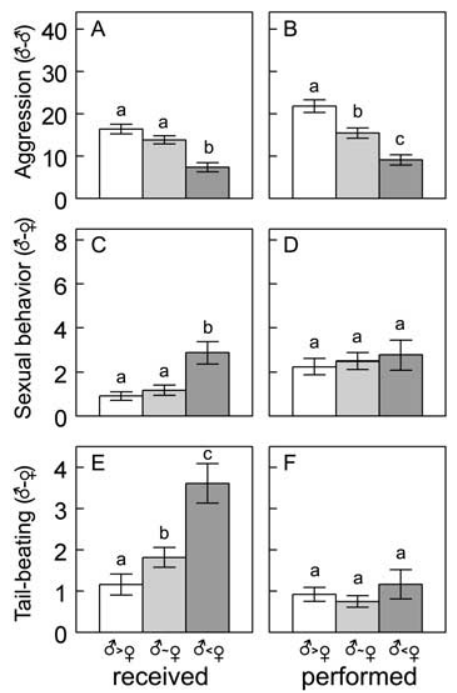

Fig. 2. Effect of OSR manipulation on social behavior of males. Data are expressed as mean \pm SEM, in frequency per 20 min focal observations. Groups: male biased $(n=53)$ : $\hat{\sigma}>\uparrow$; balanced sex bias $(n=42)$ : $\hat{\sigma} \sim$ $\uparrow$; female biased $(n=22)$ : $\delta<\uparrow$; A, C, E: received behaviors; B, D, F: performed behaviors. Different letters indicate statistically significant differences for (Kruskal-Wallis one-way ANOVA followed by Dunn's posthoc test). 


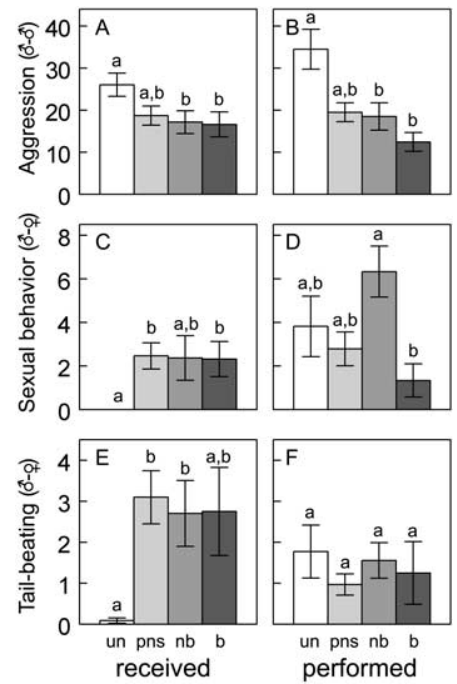

Fig. 3. Relationship between mating stage assessed at the end of the observation period and social behavior of males. Data are expressed as mean \pm SEM, in frequency per 20 min focal observations. Groups: males that were unpaired $(n=22)$ : un; males that were mated but did not spawn yet $(n=39)$ : pns; males that spawned but did not brood $(n=28)$ : nb; males that spawned and brooded $(n=28)$ : b; A,C,E: received behaviors; B,D,F: performed behaviors. Different letters indicate statistically significant differences (Kruskal-Wallis one-way ANOVA followed by Dunn's post-hoc test).

beating showed the same trend as sexual behavior (Figs. 3E-F).

\section{Behavior after spawning}

Among monogamous and polygynous males $(N=53)$, aggression received from other males differed significantly $(\mathrm{H}(2)=7.9, p<0.05)$, but not aggression towards males $(\mathrm{H}(2)=0.05$, NS). Post-hoc analyses showed that males that were deserted received significantly more aggression, than males that deserted or stayed with the partner. Sexual behavior and tail-beating directed towards deserted males did not differ between groups.

\section{Hormonal status and the effect of OSR}

The levels of T, 11-KT, 17,20 $\beta$-P, and GSI were not significantly correlated with each other. Total androgen levels were not statistically different among OSR groups (Fig. 4A). Plasma levels of 11-KT were highest in the male biased group (Fig. 4C), whereas plasma levels of $\mathrm{T}$ were highest in the female biased group (Fig. 4D). The relative amount of 11-KT was highest in the male biased group (Fig. 4B). Levels of 17,20 $\beta$-P were not affected by OSR (Fig. 4E). GSI did not differ significantly among OSR groups (Fig. 4F).

\section{Hormonal status, mating strategies and behavior}

As expected from the challenge hypothesis, aggression received from other males was positively correlated with the plasma levels of $11-\mathrm{KT}[\operatorname{Rs}(3,24)=0.31, p<0.05]$, but not with levels of T. Plasma levels of 11-KT were not significantly correlated with sexual behavior or with tailbeating received from females. However, plasma levels of $\mathrm{T}$ were positively correlated with sexual behavior $[\operatorname{Rs}(2,24)$ $=0.32, p<0.05]$ and with tail-beating $[\operatorname{Rs}(1,24)=0.40$, $p<0.001]$ received from females. An animal's own aggressive, sexual and tail beating behavior did not correlate significantly with levels of either 11-KT or T. Levels of $17,20 \beta$-P and GSI were not significantly correlated to aggressive behavior, sexual behavior or tail-beating.

\section{Mating stage}

Total androgen levels did not differ significantly between mating stages (Fig. 5A). Plasma levels of $\mathrm{T}$ and 11-KT showed opposite trends, 11-KT being highest in unpaired males (Fig. 5C) and $\mathrm{T}$ being highest in males that had spawned (Fig. 5D). Accordingly, the 11-KT fraction differed significantly between mating categories (Fig. 5B). Post-hoc analyses showed that males that had spawned had relatively low 11-KT levels compared to males that did not spawn (Fig. 5B). No significant difference was found in the 11-KT fraction between males that brooded and males that spawned but did not engage in mouth-brooding (Figs. 5B to C). 17,20 $\beta$-P and GSI did not differ significantly between males in different mating stages (Figs. 5E-F).

\section{Behavior after spawning}

None of the hormones or GSI were significantly different between males that stayed with the partner, deserted the partner or were deserted by the partner.
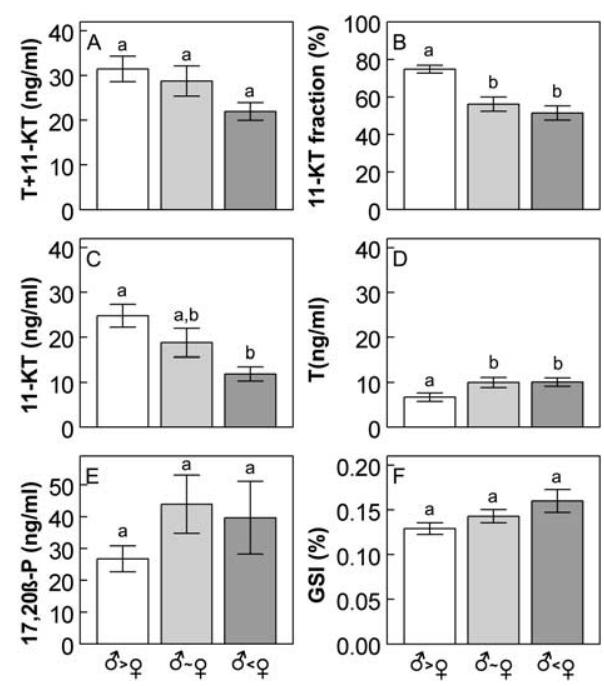

Fig. 4. Effect of OSR manipulation on plasma steroid levels and gonadosomatic index (GSI). Data are expressed as mean \pm SEM. T: testosterone; 11-KT: 11-ketotestosterone; 17,20 $\beta$-P: 17,20 $\beta$-dihydroxy-4-pregnen-3one; GSI: gonadosomatic index. Groups: male biased $(n=53)$ : $\delta>q$; balanced sex bias $(n=42)$ : $\delta \sim q$; female biased $(n=22)$ : $\hat{\delta}<q$. Different letters indicate statistically significant differences for (KruskalWallis one-way ANOVA followed by Dunn's post-hoc test). 

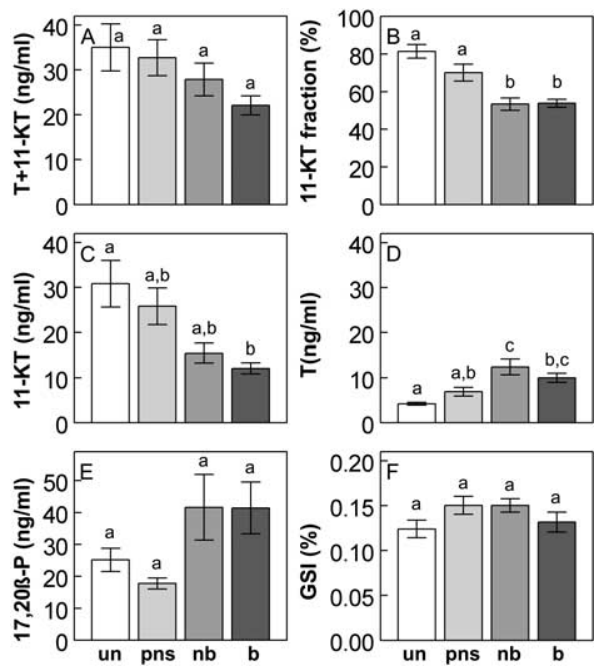

Fig. 5. Relationship between mating stage and plasma steroid levels and gonadosomatic index (GSI). Data are expressed as mean \pm SEM. T: testosterone; 11-KT: 11-ketotestosterone; 17,20 $\beta$-P: 17,20 $\beta$-dihydroxy-4pregnen-3-one; GSI: gonadosomatic index. Groups: males that were unpaired $(n=22)$ : un; males that were mated but did not spawn yet $(n=39)$ : pns; males that spawned but did not brood $(n=28)$ : nb; males that spawned and brooded $(n=28)$ : b. Different letters indicate statistically significant differences (Kruskal-Wallis one-way ANOVA followed by Dunn's post-hoc test)

\section{Discussion}

Manipulation of OSR in large semi-natural ponds resulted in correlated variation in social behavior of male $S$. galilaeus ranging from males that stayed with their partner after spawning (monogamy) to males that switched between partners (polygyny) and males that participated in parental care (mouth-brooding) or not. Males more often broke-up the pair-bond when partner availability was high (i.e., in the female biased OSR group). These results confirm earlier reports describing high plasticity in the behavior of $S$. galilaeus (Balshine-Earn, 1996; Balshine-Earn and Earn, 1998; Fishelson and Hilzerman, 2002). More importantly, the experimental set-up provided the large variation in behavior sought for to test its relationship with sex steroid levels (see below).

Five animals in the female biased group were paired with more than one female at the same time. Therefore, this type of polygyny in $S$. galilaeus probably only occurs when a strong female bias exist in the population. In natural populations this has been reported only once, whereas more frequently OSR's have been found to be slightly male biased (OSR $\delta: ?$ range: 1.6:1 to 1:3, see Iles and Holden, 1969; Balshine-Earn, 1996). We therefore expect that this type of polygyny is rare in free-living animals and focus our discussion on the differences between males that break-up the pair-bond after spawning (polygynous) or stay together with the female after spawning (monogamous).

In an evolutionary model Balshine-Earn and Earn (1997) showed that reproductive "decisions" of male $S$. galilaeus depend on the availability of mates in the population. If females are overabundant, the expected stable strategy is female brooding, whereas males defer from brooding and try to maximize the number of breeding attempts. Since in this species females can spawn several times, the opposite is expected when males are overabundant. This fits our observation that female biased OSR promoted male mate desertion after spawning. Similar results have been obtained by Fishelson and Hilzerman (2002) with an even higher male to female OSR (1:3). Although there was a similar trend for females, it was not statistically significant, probably because of the low frequency of desertion by females. The phenomenon of partner desertion is well studied in birds and is often referred to as "divorce" (Choudhury, 1995). Many functional theories exist to explain why animals divorce or are faithful to their partner. Animals are thought to divorce when this will improve their reproductive success. It generally happens when perceived better non-brooding partners are available. Therefore, divorce rates should increase with greater availability of unpaired individuals in the population (reviewed by Choudhury, 1995).

Significantly more aggressive behavior was found in male biased groups, and more sexual behavior in female biased groups. This is what would be expected from the opportunity for male-male competition (Jirutkul, 2000). Furthermore, unpaired males compared to paired individuals were more aggressive and received more aggression. Nearly all unpaired males were territorial and often courted already paired females. In addition, unpaired males were often chased out of their territory by other males. Males that were paired were less aggressive but were rarely chased off their territory (Ros personal observations). It is likely that the share of territorial defense by male and female explains this difference (see also Fishelson, 1983; Fishelson and Hilzerman, 2002).

As expected from the trade off between territorial behavior and parental behavior (e.g., Wingfield et al., 1990), aggression was lowest in brooding animals. However many of these animals remained territorial and were aggressive to intruders often by butting or pendulum threat with closed mouth. Earlier studies assumed that pairs stop being territorial after spawning based on the observation that individuals swim away from the territory after they spawned (see Balshine-Earn, 1996). However, our own results and those of Fishelson and Hilzerman (2002), show that pairs may stay together. A field study following marked individuals should be conducted to know whether in nature monogamous pairs return to the same territory in subsequent spawnings.

The primary prediction of the challenge hypothesis is that social challenges increase androgen levels (Wingfield et al., 1990). In accordance with this prediction, the levels of 11-KT were highest in the male biased OSR group which had the highest levels of male-male aggression. 11-KT levels were also higher in males that were unpaired compared to paired males. These males were the most aggres- 
sive and received the most aggression. Furthermore, levels of 11-KT were positively correlated with received aggressive behavior. Since the individuals with high 11-KT levels were most active in territorial behavior this suggests that in fish, as well as in birds (e.g., Wingfield et al., 1990; Groothuis and Meeuwissen, 1992; Ros et al., 2002), a positive feedback mechanism is operative between external stimulation, androgens (specifically 11-KT) and aggressive behavior (see Oliveira et al., 2002).

The second prediction was that polygynous males should have higher levels of androgens than monogamous males since they are more active in searching for females and therefore more challenged by other males. However, our results do not appear to support this prediction. Polygynous males (i.e., males that deserted their females after spawning) did not differ in androgen levels, 11-KT or T, from monogamous males (i.e., males that stayed with their females after spawning). Nevertheless, unlike what would be expected, our polygynous males were not more aggressive and did not receive more aggression than monogamous males. Polygyny in our experiment appeared to be a consequence of the manipulation of OSR, which provided an excess of females and lower male-male competition in one experimental group (where polygyny was more frequent). Males in this female-biased OSR group received more sexual behavior from females than males in the male-biased OSR group, indicating high female competition in the female-biased OSR group. In nature and among birds (where this has been mostly studied), polygynous males search for females in other male's territories, and this would normally involve disputes between males (Wingfield, 1984a, Ketterson and Nolan, 1992; De Ridder et al., 2000). Whether androgens still play a regulatory role in the causation of polygyny in S. galilaeus or whether OSR and thus partner availability is the main determinant for polygyny, independently of androgens, still needs to be determined by experimental manipulations.

The third prediction from the challenge hypothesis was that the levels of androgens should decrease during parental care (Wingfield et al., 1990) and in fish several studies have shown 11-KT levels to be lower in brooding than in nonbrooding males (see Oliveira et al., 2002 for a review). As already discussed above, we found that aggressive behavior and sexual behavior declined in animals that brooded eggs. In addition, levels of 11-KT were lower in animals that spawned in comparison with animals that did not spawn. However, after spawning 11-KT levels did not differ between animals that brooded versus those that did not brood. This suggests that spawning rather than brooding is the causal factor explaining the decrease in 11-KT levels (see Oliveira et al., 2001a; Oliveira et al., 2001c) and is consistent with observations in other teleosts in which $11-\mathrm{KT}$ is highest during testicular growth (Schulz et al., 2001; Weltzien et al., 2002). High 11-KT levels have been found to be inhibitory for the final stages of testis maturation (Ikuta et al., 1987). In addition, the down-regulation of 11-KT pro- duction might play a role in decreasing the male's effort in courtship and territorial behavior, which allows spending more time in overt sexual behavior resulting in spawning. Moreover, experimentally increasing plasma androgen levels in male bluegill had no effect on parental care (Kindler et al., 1991; see also Townsend et al., 1991). In birds, parental care might be a special case since egg brooding and caring for young is not compatible with courtship related activities and therefore testosterone has to be down regulated during the parental phase, and a negative correlation between testosterone and prolactin has been found (Ziegler, 2000). However, in some other vertebrates, like in the mouth-brooding S. galilaeus, courtship and aggressive competition may continue (Balshine-Earn, 1995; this study), and this might explain the lower reduction in androgen levels during the period of parental care.

11-KT levels were highest in the male biased group and lowest in the female biased group. $T$ was highest in the female biased group, which had simultaneously the highest incidence of brooding and the lowest levels of aggressive behaviors. This resulted in an inverse relationship between levels of $\mathrm{T}$ and those of 11-KT that was mediated by OSR. The inverse relationship between 11-KT and $\mathrm{T}$ is probably due to socially induced individual differences in the activity of testicular $11 \beta$-hydroxylase, required to convert $\mathrm{T}$ or androstenedione to 11-oxygenated androgens, similarly to what has been observed in Siamese fighting fish (Betta splendens) during social hierarchy formation (Leitz, 1987). This enzyme might therefore be a key regulator of androgen mediated social interactions. Effects of social stimuli on key steroidogenic enzymes for the synthesis of steroid mediators of behavior has been shown in doves for aromatase, the enzyme that converts testosterone in the brain to its active metabolite 17 $\beta$-estradiol (Hutchison and Steimer, 1985). Since we measured higher levels of 11-KT than testosterone in blood plasma, small changes in enzyme activity might cause correlated changes in both 11-KT and T levels.

We did not find any significant relationship between OSR, mating category and the levels of $17,20 \beta-\mathrm{P}$ or gonadosomatic index. In addition, total androgen levels were not different between OSR groups and between mating categories. This suggests that the average testicular activity was not different amongst OSR and mating category groups, which is in accordance with the fact that all males were active in behaviors typical for the reproductive season, which are defending territories and/or courting females.

In conclusion levels of 11-KT, the active metabolite of T in fish, supported the central postulate of the challenge hypothesis that androgen levels are a function of the social environment. 11-KT levels correlated with OSR, received territorial aggression and aggression towards other males. However, levels of 11-KT did not differ between polygynous and monogamous males nor were significantly reduced in males that participated in parental care. Therefore, these later results do not support a positive relationship between polygamy and androgen levels, and a negative relationship 
between parental care and androgen levels, both predicted for birds from the challenge hypothesis.

\section{Acknowledgments}

The authors would like to dedicate this paper to Prof. Dr. Lev Fishelson (Tel Aviv University, Israel) on the occasion of his 80th birthday. Without his enthusiasm and support this project would not have been feasible. The authors also thank Dr. Noam Werner (Tel Aviv University, Israel) and Dr. Tamir Ezer and co-workers at the Experimental Station for Aquaculture, Dept. of Fisheries, Israel, for making available the facilities and help in obtaining and maintaining the fish and the pleasant working environment. The research described here is part of a research grant awarded to RFO by the Portuguese Foundation for Science and Technology (PRAXIS/P/BIA/10251/1998). AFHR was being supported by a post-doc fellowship within the scope of this grant. RFO's research is supported by the Plurianual Program of FCT (R\&D Unit 331/94) and the initial visits of RFO to Lake Kinneret to develop this project were funded by the Israeli Embassy in Lisbon. We thank Dr. Ton Groothuis of the University of Groningen to make it possible for AFHR and IZ to participate in the research project. The "Stichting Groninger Universiteitsfonds" and the "Marco Polo Fonds" funded travels of IZ between the Netherlands, Israel and Portugal.

\section{References}

Balshine-Earn, S., 1995. The costs of parental care in Galilee St. Peter's fish, Sarotherodon galilaeus. Anim. Behav. 50, 1-7.

Balshine-Earn, S., 1996. Reproductive rates, operational sex-ratios and mate choice in St. Peter's fish. Behav. Ecol. Sociobiol. 39, 107-116.

Balshine-Earn, S., 1997. The benefits of uniparental versus biparental mouth brooding in Galilee St. Peter's fish. J. Fish Biol. 50, 371-381.

Balshine-Earn, S., Earn, D.J.D., 1998. On the evolutionary pathway of parental care in mouth-brooding cichlid fish. Proc. R. Soc. Lond. B. Biol. Sci. 256, 2217-2222.

Beletsky, L.D., Gori, D.F., Freeman, S., Wingfield, J.C., 1995. Testosterone and polygyny in birds, in: Power, D.M. (Ed.), Current Ornithology, vol 10, Plenum Press, New York, pp 1-41.

Ben-Tuvia, A., Davidoff, E.B., Shapiro, J., Shefler, D., 1992. Biology and management of lake Kinnereth fisheries. Isr. J. Aquac.-Bamidgeh. 44, $48-65$.

Canario, A.V.M., Scott, A.P., Flint, A.P.F., 1989. Radioimmunoassay investigations of $20 \beta$-hydroxylated steroids in maturing/ovulating female rainbow trout (Salmo gairdneri). Gen. Comp. Endocrinol. 74, $77-84$.

Choudhury, S., 1995. Divorce in birds: a review of the hypothesis. Anim Behav. 50, 413-429.

De Ridder, E., Pinxten, R., Eens, M., 2000. Experimental evidence of a testosterone-induced shift from paternal to mating behaviour in a facultatively polygynous songbird. Behav. Ecol. Sociobiol. 49, 24-30.

Fishelson, L., 1983. Social behavior of adult tilapia fish in captivity (Israel), in: Fishelson, L., Yaron, Z. (Eds.), Proceedings of the International Symposium on Tilapia in Aquaculture, Tel Aviv University Press, Tel Aviv, pp. 48-58.
Fishelson, L., Hilzerman, F., 2002. Flexibility in reproductive styles of male St. Peter's tilapia, Sarotherodon galilaeus (Cichlidae). Env. Biol. Fish. 63, 173-182.

Groothuis, T., Meeuwissen, G., 1992. The influence of testosterone on the development and fixation of the form of displays in two age classes of young black-headed gulls. Anim. Behav. 43, 189-208.

Hegner, R.E., Wingfield, J.C., 1986. Behavioral and endocrine correlates of multiple brooding in the semicolonial house sparrow Passer domesticus. 1. Males. Horm. Behav. 20, 294-312.

Hutchison, J.B., Steimer, T., 1985. Preoptic formation of $17 \beta$-oestradiol is influenced by behavioural stimuli in the dove. Brain Res. 360, 366369.

Ikuta, K., Aida, K., Okumoto, N., Hanyu, I., 1987. Effects of sex steroids on the smoltification of masu salmon, Oncorhynchus masou. Gen. Comp. Endocrinol. 65, 99-110.

Iles, T.D., Holden, M.J., 1969. Bi-parental mouth brooding in Tilapia galilaea (Pisces, Cichlidae). J. Zool. Lond. 158, 327-333.

Jirutkul, M., 2000. Operational sex-ratio influences the opportunity for sexual selection in guppies. J. Fish Biol. 56, 739-741.

Ketterson, E.D., Nolan Jr., V., 1992. Hormones and life histories: an integrative approach. Am. Nat. 140, 533-562.

Kimbal, R.T., Ligon, J.D., 1999. Evolution of avian plumage dichromatism from a proximate perspective. Am. Nat. 154, 182-193.

Kime, D.E., Manning, N.J., 1982. Seasonal patterns of free and conjugated androgens in the brown trout Salmo trutta. Gen. Comp. Endocrinol. 48, 222-231.

Kindler, P.M., Bahr, J.M., Philipp, D.P., 1991. The effects of exogenous 11-ketotestosterone, testosterone, and cyproterone acetate on prespawning and parental care behaviors of male bluegill. Horm. Behav. $29,410-423$.

Leitz, T., 1987. Social control of testicular steroidogenic capacities in the Siamese fighting fish Betta splendens Regan. J. Exper. Zool. 244, 473-478.

Nelson, R.J., 1999. An introduction to behavioural endocrinology. Sinauer Assoc, Sunderland, MA.

Oliveira, R.F., Almada, V.C., Canario, A.V.M., 1996. Social modulation of sex steroid concentrations in the urine of male cichlid fish Oreochromis mossambicus. Horm. Behav. 30, 2-12.

Oliveira, R.F., Canario, A.V., Grober, M.S., Santos, R.S., 2001a. Endocrine correlates of male polymorphism and alternative reproductive tactics in the Azorean rock-pool blenny, Parablennius sanguinolentus parvicornis. Gen. Comp. Endocrin. 121, 278-88.

Oliveira, R.F., Lopes, M., Carneiro, L.A., Canario, A.V.M., 2001b. Watching fights raises fish hormone levels-Cichlid fish wrestling for dominance induce an androgen surge in male spectators. Nature 409, $475-475$

Oliveira, R.F., Ros, A.F.H., Hirschenhauser, K., and Canario, A.V.M. 2001c. Androgens and Mating Systems in Fish: Intra- and Inter-specific Analysis. In H. J. Th. Goos, R. K. Rastogi, H. Vaudry, and R. Pierantoni. (eds) Perspective in Comparative Endocrinology: Unity and Diversity. Monduzzi Editore, Sorrento, Italy, pp. 985-993.

Oliveira, R.F., Hirschenhauser, K., Carneiro, L.A., Canario, A.V.M., 2002. Social modulation of androgen levels in male teleost fish. Comp. Biochem. Physiol. 132B, 203-215.

Oring, L.W., Fivizzani, A.J., Colwell, M.A., Halawani, M.E., 1988. Hormonal changes associated with natural and manipulated incubation in the sex-role reversed Wilson's phalarope. Gen. Comp. Endocrinol. 72, $247-56$.

Owens, I.P.F., Short, R.V., 1995. Hormonal bases of sexual dimorphism in birds: implications for new theories of sexual selection. Trends Ecol. Evol. 10, 44-47.

Ros, A.F.H., Dieleman, S.J., Groothuis, T.G.G., 2002. Social stimuli, testosterone, and aggression in gull chicks: support for the challenge hypothesis. Horm. Behav. 41, 334-342.

Schulz, R.W., Vischer, H.F., Cavaco, J.E.B., Santos, E.M., Tyler, C.R., Goos, H.J.Th., Bogerd, J., 2001. Gonadotropins, their receptors, and the 
regulation of testicular functions in fish. Comp. Bioch. Physiol. B 129, 407-417.

Schwanck, E., Rana, K., 1991. Male-female parental roles in Sarotherodon galilaeus (Pisces:Cichlidae). Ethology 89, 229-243.

Scott, A.P., Vermeirssen, E.L.M., 1994. Production of conjugated steroids by teleost gonads and their role as pheromones, in: Davey, K.G., Peter, R.E., Tobe, S.S. (Eds.), Perspectives in comparative endocrinology, National Research Council of Canada, Ottawa, pp. 645-654.

Scott, A.P., MacKenzie, D.S., Stacey, N.E., 1984. Endocrine changes during natural spawning in the white sucker, Catostomus commersoni. II. Steroid hormones. Gen. Comp. Endocrinol. 56, 349-359.

Silverin, B., 1993. Territorial aggressiveness and its relation to the endocrine system in the pied flycatcher. Gen. Comp. Endocrinol. 89, 206213.

Townsend, D.S., Palmer, B., Guillette Jr., L.J., 1991. The lack of influence of exogenous testosterone on male parental behavior in a neotropical frog (Eleutherodactylus): a field experiment. Horm. Behav. 25, $313-$ 322.

Weltzien, F., Taranger, G.L., Karlsen, O., Norberg, B., 2002. Spermatogenesis and related plasma androgen levels in Atlantic halibut
(Hippoglossus hippoglossus L.). Comp. Bioch. Physiol. A 132, 567-575.

Wingfield, J.C., 1984a. Androgens and mating systems: testosterone-induced polygyny in normally monogamous birds. Auk 101, 665-671.

Wingfield, J.C., 1984b. Environmental and endocrine control of reproduction in the song sparrow, Melospiza melodia. II. Agonistic interactions as environmental information stimulating secretion of testosterone. Gen. Comp. Endocrinol. 56, 417-424.

Wingfield, J.C., Moore, M.C., 1987. Hormonal, social, and environmental factors in the reproductive biology of free-living male birds. In Crews, D. (Ed.), Psychobiology of Reproductive Behavior-an evolutionary perspective. Prentice Hall, Englewood Cliffs, 291-322.

Wingfield, J.C., Hegner, R.E., Dufty Jr., A.M., Ball, G.F., 1990. The "challenge hypothesis:" theoretical implications for patterns of testosterone secretion, mating systems, and breeding strategies. Am. Nat. 136, 829-846.

Zar, J.H., 1984. Biostatistical analysis. Prentice Hall, Englewood Cliffs, New Jersey.

Ziegler, T.E., 2000. Hormones associated with non-maternal infant care: A review of mammalian and avian studies. Folia Primatologia 71, 6-21. 